\title{
ROLE OF ADRENERGIC RECEPTORS IN THE CENTRAL THERMOREGULATORY MECHANISM OF THE RAT
}

\author{
Naoki Fukushima and Shinji IтоH \\ Department of Physiology, Hokkaido University School of Medicine, \\ Sapporo 060, Japan
}

\begin{abstract}
Changes in rectal and skin temperatures following intraventricular injection of norepinephrine and receptor specificity of the response in the rat were investigated.

Intraventricular injection of norepinephrine in a small dose $(6 \mu \mathrm{g})$ produced a slight elevation in rectal temperature, but in larger amounts $(25-50 \mu \mathrm{g})$ the result was a dose-dependent hypothermia associated with a marked rise in skin temperature. No change was observed in oxygen consumption after intraventricular injection of norepinephrine $(25 \mu \mathrm{g})$. Intraventricular injection of phenoxybenzamine prior to norepinephrine blocked hypothermia and skin temperature elevation which are normally observed following norepinephrine injection, while propranolol given in the same way showed less or no effect. Intraventricular injection of phenylephrine produced a dose-dependent hypothermia, whereas a no does-response relationship was obtained with isoproterenol.

These results suggest that in the rat the hypothermic effect of norepinephrine injected intraventricularly is mediated by the action of central alpha receptors.
\end{abstract}

The concept that body temperature is regulated by a fine balance in the release of catecholamines and 5-hydroxytryptamine in the anterior hypothalamus was first proposed by FELDBERG and MYERS $(1963,1964,1965)$ who studied changes in body temperature following central administration of these amines in unanesthetized cats. Many subsequent investigators have revealed considerable species differences in the direction and magnitude of rectal temperature changes. In the rat, intraventricular injection of a small dose $(2-6 \mu \mathrm{g})$ of norepinephrine produced an increase in rectal temperature preceded by a brief fall (FELDBERG and LotTI, 1967; BRuINVels, 1970), whereas larger doses $(10-50 \mu \mathrm{g})$ of the amine have been reported to elicit either hypothermia (FELDBERG and LoTTI, 1967;

Received for publication April 25, 1975

福島直樹, 伊藤真次 
Bruinvels, 1970) or hyperthermia (MYers and YAKSH, 1968; BeCKMAN, 1970). Thus, the primary effect of centrally applied norepinephrine in the rat is not clear.

The existence of central adrenergic receptors has been demonstrated, but they may not be necessarily related to their known actions on peripheral receptors. There is evidence to indicate that the hypothermia elicited by norepinephrine injected into the hypothalamus or the lateral ventricle of the mouse (BRITTAIN and HANDley, 1967), cat (BuRKs, 1972; Rudy and Wolf, 1971) and golden hamster (REIGLE and WOLF, 1974) may be due to action on central receptors of the alpha type. In the rat, however, the role of adrenergic receptors on central thermoregulation has not been shown. Accordingly, the present experiments were undertaken to investigate the dose-dependent characteristics and receptor specificity of the central thermoregulation induced by injection of norepinephrine into the lateral ventricle of the rat.

\section{MATERIALS AND METHODS}

Male albino rats of the Wistar strain, weighing from 250 to $350 \mathrm{~g}$, were used for all experiments. They were housed in an air-conditioned $\left(23 \pm 2^{\circ} \mathrm{C}\right)$ and light-controlled (lights on from $6: 30$ am to $6: 30 \mathrm{pm}$ ) room and allowed access to food (Oriental MF) and water ad libitum.

Animals were anesthetized with sodium pentobarbital $(50 \mathrm{mg} / \mathrm{kg}$ i.p.) and a No. 5 polyethylene tube cannula with an outer diameter of $0.8 \mathrm{~mm}$ and a length of $2 \mathrm{~cm}$ was implanted aseptically into the right lateral ventricle utilizing a stereotaxic technique. The cannula was placed $2.5 \mathrm{~mm}$ lateral to the sagittal suture and $1 \mathrm{~mm}$ posterior to the coronal suture and opening of the cannula tip was $4 \mathrm{~mm}$ below the skull surface. The cannula was permanently affixed to the skull with dental cement. After surgery the animals were housed in individual cages and given antibiotics parenterally for 5 days. After a week, the animals recovered and were gentled by daily manual handling. One day before the experiment, $7.5 \mu \mathrm{l}$ isotonic saline was injected into the ventricle through the implanted cannula. In order to verify the cannula placement, at the end of experiment $7.5 \mu \mathrm{l}$ methylen blue was injected through the cannula and the dye that spread in the ventricular systems was examined macroscopically.

Rectal temperature at a depth of $5 \mathrm{~cm}$ from the anus and the skin temperature of the tail were measured by using a thermister at $10 \mathrm{~min}$ intervals before and after intraventricular injection of drugs. Heat production was estimated from the rate of oxygen consumption employing an closed-circuit spirometer by Collins.

All drugs were dissolved in $0.9 \%$ sodium chloride solution just prior to use. $7.5 \mu \mathrm{l}$ of the drug solution was injected by microsyringe through the cannula into the lateral ventricle. All experiments were performed in an unanesthetized state at an ambient temperature of $23 \pm 2{ }^{\circ} \mathrm{C}$.

Drugs used were as follows: L-norepinephrine bitartarate (Wako Chemical 
Co.), sodium bitartarate (Kanto Chemical Co.), tartaric acid (Kanto Chemical Co.), propranolol hydrochloride (Sigma Chemical Co.), isoproterenol bitartarate (Sigma Chemical Co.), phenoxybenzamine hydrochloride (Nakarai Chemical Co.) and phenylephrine hydrochloride (Sigma Chemical Co.). Doses of norepinephrine and isoproterenol were calculated on the basis of the free base and other drugs on the basis of the salts.

\section{RESULTS}

Effect of intraventricular injection of norepinephrine

As shown in Fig. 1, norepinephrine injected intraventricularly produced a dose-dependent decrease in the rectal temperature. The maximal effect was seen after $15-30 \mathrm{~min}$ and the temperature returned to the initial level after $90 \mathrm{~min}$. The repeated injection of this amine $(25 \mu \mathrm{g})$ resulted in the same decrease in rectal temperature as with the first injection. Hypothermia induced by norepinephrine was associated with a marked rise of skin temperature (Fig. 2). No change was observed in oxygen consumption after the injection of norepinephrine in a dose of $25 \mu \mathrm{g}$ (Fig. 2). Intraperitoneal injection of norepinephrine in a dose of $300 \mu \mathrm{g}$, intraventricular injection of sodium bitartarate and tartaric acid both in a dose $25 \mu \mathrm{g}$, and $0.01 \mathrm{~N} \mathrm{HCl}$ had no effect on the rectal temperature, respectively.

\section{Effects of adrenergic blocking agents on norepinephrine-induced hypothermia}

Pretreatment with alpha-receptor blocking agents, phenoxybenzamine $(6 \mu \mathrm{g})$,

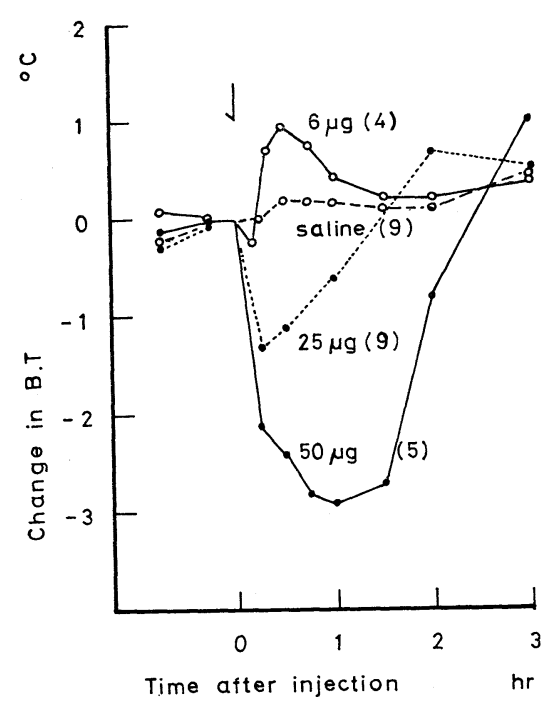

Fig. 1. Effect of intraventricular injection of norepinephrine $(6,25$, and $50 \mu \mathrm{g})$ on rectal temperature. The arrow indicates the time of injection. Numbers in parentheses represent number of rats. 


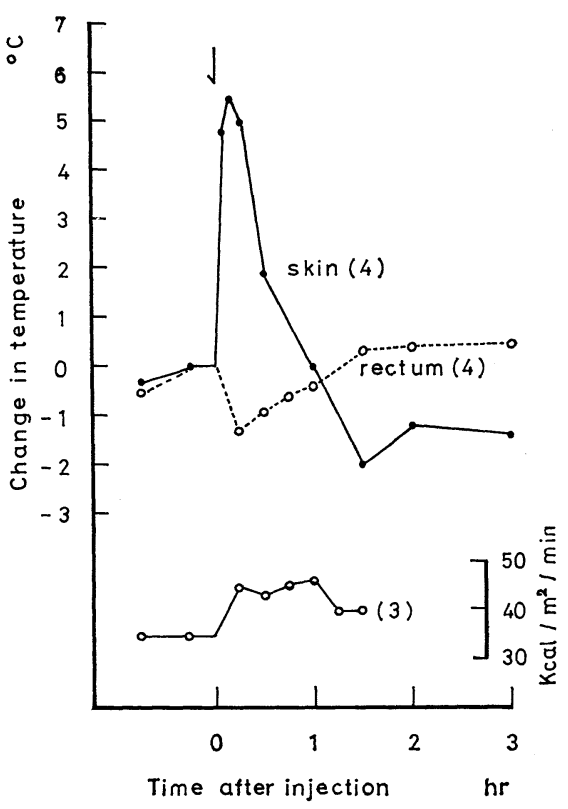

Fig. 2. Effect of intraventricular injections of norepinephrine $(25 \mu \mathrm{g})$ on skin temperature, rectal temperature and oxygen consumption. - - - skin temperature, ---○--: rectal temperature, - $\mathrm{O}-$ : oxygen consumption.

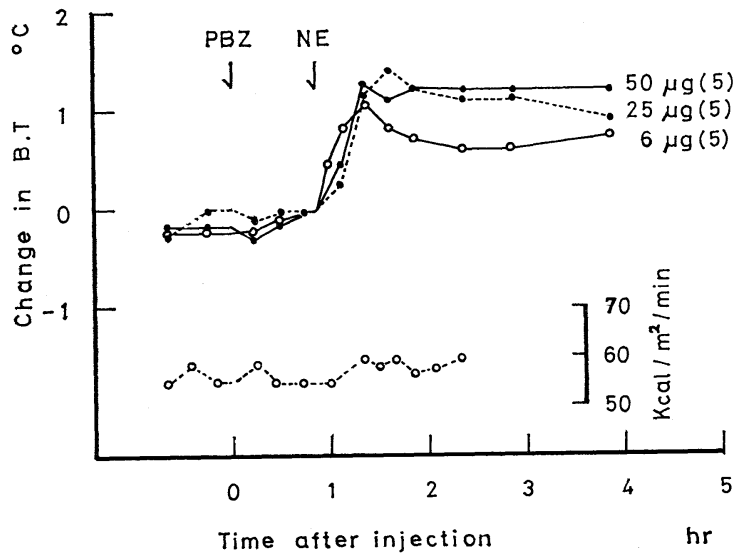

Fig. 3. Effect of phenoxybenzamine pretreatment on norepinephrine-induced hypothermia. Phenoxybenzamine $(6 \mu \mathrm{g})$ was injected 50 min prior to norepinephrine injection $(6,25$, and $50 \mu \mathrm{g})$. Effect of norepinephrine $(25 \mu \mathrm{g})$ on oxygen consumption in phenoxybenzamine $(6 \mu \mathrm{g})$ pretreated rats (---○---). At the first arrow phenoxybenzamine was injected and at the second arrow (50 min later) norepinephrine was injected. 
not only blocked norepinephrine-induced hypothermia, but produced a rise in the rectal temperature of approximately $1^{\circ} \mathrm{C}$ following the norepinephrine injection in doeses of 6-50 $\mu \mathrm{g}$ (Fig. 3). Simultaneous injection of phenoxybenzamine and

Table 1. Effect of simultaneous injection of phenoxybenzamine or propranolol and norepinephrine into the lateral ventricle on rectal temperature. Numbers in the parentheses represent standard errors of the mean.

\begin{tabular}{crrrrr}
\hline \multirow{2}{*}{ Drugs } & \multicolumn{5}{c}{ Change in rectal temperature after injection $\left({ }^{\circ} \mathrm{C}\right)$} \\
\cline { 2 - 6 } & \multicolumn{1}{c}{15} & 30 & 60 & 120 & $180 \mathrm{~min}$ \\
\hline $\mathrm{NE}(25 \mu \mathrm{g})$ & $-1.3(0.2)$ & $-1.1(0.3)$ & $-0.6(0.4)$ & $0.7(0.1)$ & $0.5(0.2)$ \\
$\mathrm{PBZ}(6 \mu \mathrm{g})$ & $0.1(0.0)$ & $0.2(0.2)$ & $0.2(0.2)$ & $1.3(0.4)$ & $1.1(0.4)$ \\
$\mathrm{NE}(25 \mu \mathrm{g})$ & & $-0.7(0.1)$ & $0.1(0.3)$ & $0.9(0.2)$ & $1.4(0.2)$ \\
$\mathrm{P} \quad(25 \mu \mathrm{g})$ & $-1.4(0.0)$ & $-0.7)$ &
\end{tabular}

NE: norepinephrine, PBZ: phenoxybenzamine, $\quad$ P: propranolol.

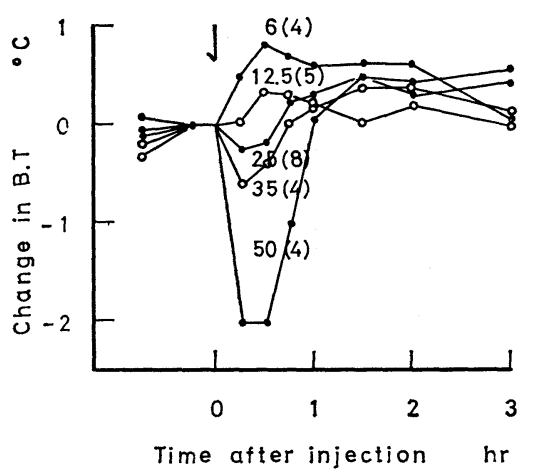

Fig. 4. Effect of intraventricular injection of phenylephrine $(6,12.5,25,35$, and $50 \mu \mathrm{g})$ on rectal temperature.

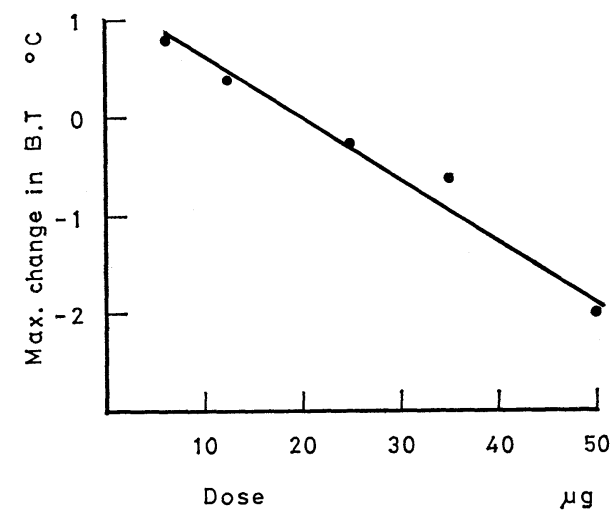

Fig. 5. Relationship between doses of phenylephrine and maximum change in rectal temperature during a period of 1 hour after intraventricular injection of phenylephrine. 


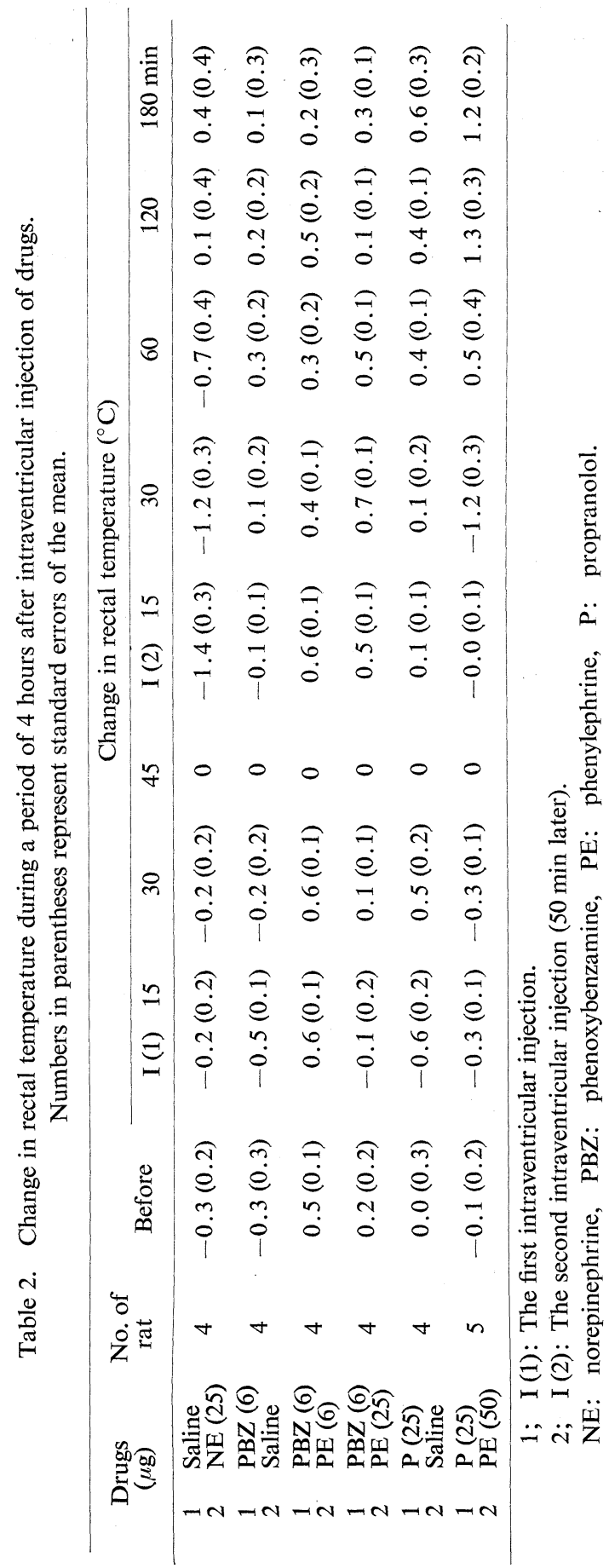


norepinephrine resulted in the same change in rectal temperature as observed in phenoxybenzamine-pretreated rats (Table 1). No change was demonstrated in oxygen consumption when norepinephrine $(25 \mu \mathrm{g})$ was administered in phenoxybenzamine-pretreated animals (Fig. 3).

The intraventricular injection of alpha-receptor agonist, phenylephrine (6$50 \mu \mathrm{g}$ ), brought about a dose-dependent decrease in the rectal temperature (Figs. $4,5)$. The hypothermic effect of phenylephrine was blocked by the prior administration of phenoxybenzamine (Table 2).

On the other hand, beta-receptor blocking agent, propranolol $(12.5 \mu \mathrm{g})$, given in the same way, showed no effect (Fig. 6). The intraventricular injection of propranolol in a dose of $25 \mu \mathrm{g}$ prior to norepinephrine $(25 \mu \mathrm{g})$ abolished the

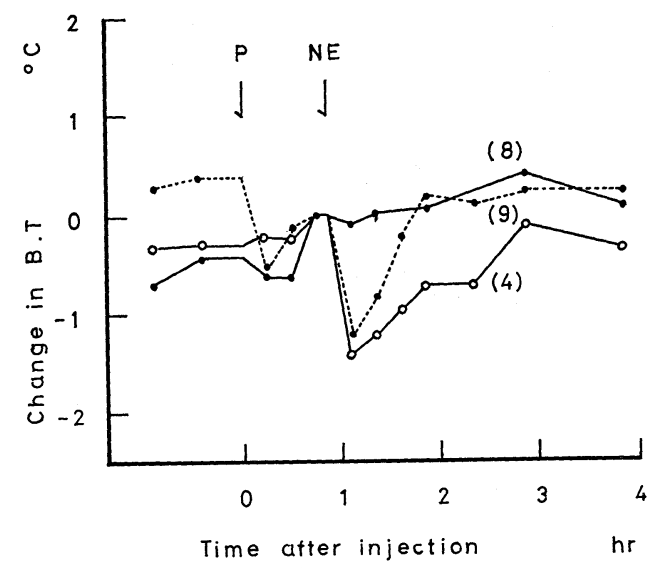

Fig. 6. Effect of propranolol pretreatment on norepinephrine-induced hypothermia. At the first arrow propranolol or saline was injected and at the second arrow (50 min later) norepinephrine was injected. - - - : saline + norepinephrine $25 \mu \mathrm{g}$, -.-๑---: propranolol $12.5 \mu \mathrm{g}+$ norepinephrine $25 \mu \mathrm{g}, \ldots-$ : propranolol $25 \mu \mathrm{g}+$ norepinephrine $25 \mu \mathrm{g}$.

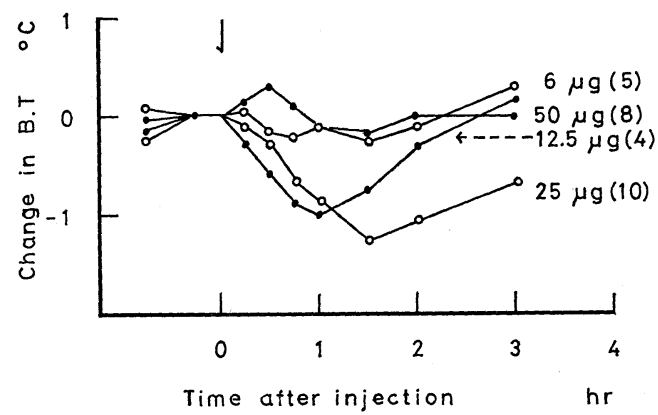

Fig. 7. Effect of intraventricular injection of isoproterenol $(6,12.5,25$, and $50 \mu \mathrm{g})$ on rectal temperature. 


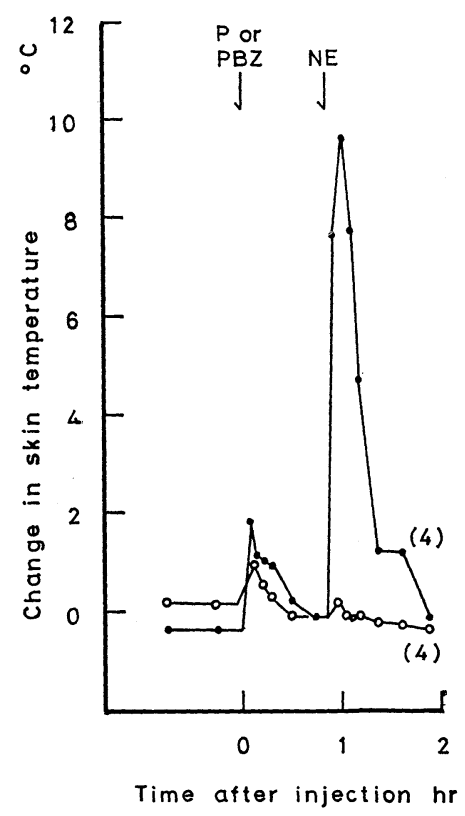

Fig. 8. Effect of propranolol $(25 \mu \mathrm{g})$ or phenoxybenzamine $(6 \mu \mathrm{g})$ pretreatment on the skin temperature elevation caused by norepinephrine $(25 \mu \mathrm{g})$. At the first arrow propranolol or phenoxybenzamine was injected and at the second arrow (50 min later) norepinephrine was injected. - - : propranolol $25 \mu \mathrm{g}$ + norepinephrine $25 \mu \mathrm{g}$, - $\mathrm{O}-$ : phenoxybenzamine $6 \mu \mathrm{g}+$ norepinephrine $25 \mu \mathrm{g}$.

hypothermia which is normally observed following norepinephrine injection (Fig. 6). But propranolol injected simultaneously with norepinephrine showed no effect (Table 1). Moreover, no dose-response relationship was obtained by the intraventricular injection of beta-receptor agonist, isoproterenol, in doses of 6$50 \mu$ g (Fig. 7).

Skin temperature elevation induced by norepinephrine was blocked by phenoxybenzamine pretreatment prior to norepinephrine administration, whereas propranolol had no effect in this respect (Fig. 8).

\section{DISCUSSION}

Intraventricular injection of norepinephrine in a small dose $(6 \mu \mathrm{g})$ produced a slight elevation of the rectal temperature, but in larger doses $(25-50 \mu \mathrm{g})$ resulted in a dose-dependent hypothermia. These results are consistent with others' findings (FELDBERG and LOTTI, 1967; BRUINVELS, 1970). When norepinephrine was intraperitoneally administered in a dose of $300 \mu \mathrm{g}$, no temperature effect was obtained. Moreover, systemic blood pressure did not change following intraventricular injection of norepinephrine in a dose of $25 \mu \mathrm{g}$ (ABE and HrRoshige, 1974). Accordingly, it would appear that norepinephrine injected into the lateral 
ventricle acts on the central nervous system directly. In addition, since intraventricular injection of tartaric acid, sodium bitartarate, $0.01 \mathrm{~N} \mathrm{HCl}$ and isotonic saline had no influence on body temperature, it is inferred that the observed effect is due to the action of norepinephrine itself.

It has been pointed out that these responses are possibly pharmacological artifacts of norepinephrine, since the quantities of intraventricularly injected norepinephrine is considerably large in comparison with the hypothalamic content of norepinephrine. The necessity for high dose of norepinephrine could conceivably be explained by rapid removal of the substance by diffusion into the whole ventricular system, uptake by the capillaries and nerve endings, extracellular binding and metabolism by catechol-O-methyltransferase. So it is presumed that the amount of exogenous norepinephrine which can arrive at postsynaptic receptors is relatively small.

We had reported that 6-hydroxydopamine, imipramine and safrazine produced a fall in the rectal temperature which was similar to that produced by norepinephrine and that norepinephrine-induced hypothermia was more pronounced in rats pretreated with these substances (Fukushima, 1975). Furthermore, depletion of endogenous norepinephrine by $\alpha$-methyl- $p$-tyrosine was shown to reduce the thermoregulatory response of norepinephrine (FUKUSHIMA, 1975). These results suggest, therefore, that norepinephrine can influence the thermoregulation rather physiologically; that is intraventricularly injected norepinephrine may act on the postsynaptic receptors in the thermoregulatory neurons.

The existence of central adrenergic receptors resembling peripheral alpha (FISZER and RobeRTIS, 1968) or beta receptor (ForN et al., 1974) has been reported. Chemical stimulation of alpha receptors in the hypothalamus of the rat elicits hunger (BOOTH, 1968; LEIBOWITZ, 1971; BERGER et al., 1971), whereas stimulation of beta receptors in the same region suppresses eating (LEIBOwITZ, 1971).

Our results showed that the effect of intraventricular injection of norepinephrine was diminished by pretreatment with phenoxybenzamine and that a good dose-response relationship was obtained in the rectal temperature changes following intraventricular injection of phenylephrine $(6-50 \mu \mathrm{g})$. Therefore, it is suggested that norepinephrine produces hypothermia by its action on central alpha receptors in the rat. It is interesting that when norepinephrine was given in phenoxybenzamine-pretreated rats, rectal temperature showed a rise of approximately $1^{\circ} \mathrm{C}$. These results are consistent with those reported by BuRKs (1972) and Rudy and Wolf (1971) in the cat, NaKamura and Thoenen (1971) in the rat and REIGLE and Wolf (1974) in the golden hamster.

As to beta receptors, no dose-response relationship was obtained by intraventricular injection of isoproterenol. However, the possibility that the beta receptors may participate in the central thermoregulation could not be ruled out, since the prior administration of propranolol in a dose of $25 \mu \mathrm{g}$ diminished the hypothermia induced by norepinephrine. In this regard, the capability of pro- 
pranolol to block alpha as well as beta receptors (KOHLI and LiNG, 1967; TsouCARISKUPFER and SCHMITT, 1972) or its considerable depressive and anesthetic actions on the central nervous system (LESZKOVSZKY and TARDOS, 1965; MURMANN et al., 1966) have been reported. Therefore, these actions may account for the abolishment of norepinephrine-induced hypothermia. On the other hand, MYERS and YAKSH (1968) indicated that hyperthermia induced by norepinephrine was mediated by action in central beta receptors. Our above-mentioned observation that norepinephrine could cause an elevation of body temperature in rats with alpha receptors blocked by phenoxybenzamine may suggest the hyperthermic influence of the central beta receptors. Further investigation are necessary to draw the conclusion on the significance of beta receptors in the central thermoregulation.

It is possible that intraventricular norepinephrine has an influence on the hypothalamic blood flow and hypothalamic temperature. RoSENDORFF (1974) has shown that norepinephrine injected into the hypothalamus in small doses caused an increase in hypothalamic blood flow, while larger doses were vasoconstrictive. This vasodilator effect of norepinephrine was blocked by propranolol and the vasoconstrictive effect was blocked by phenoxybenzamine. It appears thus that the beta receptor was activated by smaller dose of norepinephrine and alpha receptor by larger doses, the net effect of the larger dose being an alpha receptor vasoconstriction. It seems likely that norepinephrine causes a rise of body temperature at smaller doses and a fall at larger doses through its effect on hypothalamic blood flow. In spite of this apparent consistency, Rosendorff could not sufficiently explain the relationship between hypothalamic blood flow and rectal temperature changes in the rabbit (ROSENDORFF, 1974).

No change in oxygen consumption was observed after the intraventricular injection of norepinephrine. This implies that the norepinephrine-induced hypothermia is not resulted from decreased heat production. On the other hand, the hypothermia was associated with a marked rise of skin temperature which indicates a pronounced peripheral vasodilation. Phenoxybenzamine prevented completely the elevation of skin temperature, whereas propranolol was ineffective. These results clearly indicate that the achievement of the central thermoregulatory mechanism which is responsible for the hypothermia following centrally applied norepinephrine includes the control of peripheral vascular tone in the rat. It is also suggested that the regulation of peripheral vascular tone is mediated by central alpha adrenergic. The involvement of central alpha adrenergic receptors was similarly proposed by REIGLE and WOLF (1974) in the golden hamster. These findings indicate that the central alpha adrenergic receptors play an important role in the thermoregulation centrally as well as peripherally.

\section{REFERENCES}

Abe, K. and Hiroshige, T. (1974) Changes in plasma corticosterone and hypothalamic CRF levels following intraventricular injection or drug-induced changes of brain biogenic amines 
in the rat. Neuroendocrinology, 14: 195-211.

BECKMAN, A. L. (1970) Effect of intrahypothalamic norepinephrine on thermoregulatory responses in the rat. Am. J. Physiol., 218: 1596-1604.

Berger, B. D., Wise, C. D., and SteIn, L. (1971) Norepinephrine: Reversal of anorexia in rats with lateral hypothalamic damage. Science, 172: 281-284.

Bоoтн, D. A. (1968) Mechanism of action of norepinephrine in eliciting an eating response on injection into the rat hypothalamus. J. Pharmacol. Exp. Ther., 160: 336-348.

BritTAIN, R. T. and HANDLEY, S. L. (1967) Temperature changes produced by the injection of catecholamines and 5-hydroxytryptamine into the cerebral ventricles of the conscious mouse. J. Physiol., 192: 805-813.

Bruinvels, J. (1970) Effect of noradrenaline, dopamine and 5-hydroxytryptamine on body temperature in the rat after intracisternal administration. Neuropharmacology, 9: 277-282.

Burks, T. F. (1972) Central alpha adrenergic receptors in thermoregulation. Neuropharmacology, 11: 615-624.

FeldberG, W. and Myers, R. D. (1963) A new concept of temperature regulation by amines in the hypothalamus. Nature, 200: 1325.

FeldberG, W. and Myers, R. D. (1964) Effects on temperature of amines injected into the cerebral ventricles. A new concept of temperature regulation. J. Physiol., 173: 226-237.

Feldberg, W. and Myers, R. D. (1965) Changes in temperature produced by microinjections of amines into the anterior hypothalamus of cats. J. Physiol., 177: 239-245.

FELDBERG, W. and LotTI, V. J. (1967) Temperature responses to monoamines and an inhibitor of MAO injected into the cerebral ventricles of rats. Br. J. Pharmacol. Chemother., 31: $152-161$.

Fiszer, S. and Robertis, E. De (1968) Subcellular distribution and possible nature of the $\alpha$ adrenergic receptor in the CNS. Life Sciences, 7: part 1, 1093-1103.

Forn, J., KRUEGer, B. K., and Greengard, P. (1974) Adenosine 3', 5'-monophosphate content in rat caudate nucleus: Demonstration of dopaminergic and adrenergic receptors. Science, 186: 1118-1119.

Fukushima, N. (1975) Role of brain biogenic amines in the central thermoregulatory mechanism of the rat. Hokkaido J. Med. Sci., 50:369-385.

KoHLI, J. D. and LING, G. M. (1967) $\alpha$-Adrenergic blocking action of propranolol. J. Pharm. Pharmacol., 19: 629-631.

LEIBowitz, S. F. (1971) Hypothalamic alpha- and beta-adrenergic systems regulate both thirst and hunger in the rat. Proc. Nat. Acad. Sci., 68: 332-334.

LESZKovszKY, G. and TARDOs, L. (1965) Some effects of propranolol on the central nervous systems. J. Pharm. Pharmacol., 17: 518--519.

Murmann, W., Almirante, L., and Saccani-Guelfi, M. (1966) Central nervous system effects of four $\beta$-adrenergic receptor blocking agents. J. Pharm. Pharmacol., 18: 317-318.

MYeRs, R. D. and YAKSH, T. L. (1968) Feeding and temperature responses in the unrestrained rat after injections of cholinergic and aminergic substances into the cerebral ventricles. Physiol. Behav., 3: 917-928.

NAKamura, K. and Thoenen, H. (1971) Hypothermia induced by intraventricular administration of 6-hydroxydopamine in rats. Eur. J. Pharmacol., 16: 46-53.

Reigle, T. G. and Wolf, H. H. (1974) Potential neurotransmitters and receptor mechanisms involved in the central control of body temperature in golden hamsters. J. Pharmacol. Exp. Ther., 189: 97-109.

RoSENDORFF, C. (1974) Hypothalamic blood flow. In Recent Studies of Hypothalamic Function, ed. by Lederis, K. and CoOPER, K. E. Karger, Basel, pp. 399-407.

Rudy, T. A. and Wolf, H. H. (1971) The effect of intrahypothalamically injected sympathomimetic amines on temperature regulation in the cat. J. Pharmacol. Exp. Ther., 179: 218-235.

TSOUCARIS-KuPFER, D. and SCHMITT, H. (1972) Hypothalamic effect of $\alpha$-sympathomimetic agents and their antagonism by adrenergic and cholinergic blocking drugs. Neuropharmacology, 11: 625-635. 